Timothy G. Young

\title{
EVIDENCE: TOWARD A LIBRARY DEFINITION OF EPHEMERA
}

IN HER BOOK Evidence: The Art of Candy Jernigan, the artist works with a palette of what might be called detritus: sketches of crushed cans, cigarette packages, and burnt matches coreside with real bottle caps, crack vials, and even a stuffed rat, all of which form the substance of her work. This obsession with the rejected also is found in her travel journals, pages of which are reproduced in facsimile in the book. In these records of her travels across the United States and around the world, Jernigan ups the ante for the standard travelogue by pasting in cobwebs from the Pantheon in Paris and a piece of a tire tread from Gambia and by applying earth-toned stripes of food to record what she was eating. These journals, however, are made up principally of cancelled airline tickets, menus, invitations, wine bottle labels, colorful foreign-language advertisements, receipts, and postcards. As she herself defined the contents of the book she made during her first trip to Europe, it included "anything that would add information about a moment or a place, so that the viewer could make a new picture from the remnants."1 In the same statement of purpose, she notes that she originally began with the goal of assembling "airplane and bus and railroad ephemera" as proof of her travels. It is this category of documentary artifacts, ephemera, that she felt she had to redefine to accurately record the particulars of her peripatetic life. Jernigan's technique of combining the actual with the virtual, objects

1. Candy Jernigan, Evidence: The Art of Candy Jernigan, edited by Laurie Dolphin (San Francisco : Chronicle Books. 1999), p.4. 
with documents, adds a poignant depth to her project. As Wallace Stevens wrote in the poem "Not Ideas about the Thing, But the Thing Itself": "It was like / A new knowledge of reality." ${ }^{2}$

It is this sense of new knowledge, of evidence, that challenges our understanding of ephemera in the context of libraries and archives. Those of us actively employed in the service of library collections, and perhaps most important, special collections, like to believe we are performing the task of gathering and preserving information about moments and places. However, material that falls in the very broad category of ephemera continues to vex us. We have a difficult time categorizing it, storing it, and especially (this is at the heart of the problem) defining it. (For the purposes of arriving at a reasonable understanding of the issue, we will put aside a discussion of physical artifacts, the realia described in Jernigan's work, for now, though it can be argued that bottle caps and cigarette packages - anything bearing text—is a candidate for inclusion.)

The primary difficulty with defining ephemera comes partly from the fact that it has been circumscribed principally by example. Among the types of items that fit into the broad swath of ephemera are: keepsakes, invitations, theater programs, tickets, rewards of merit, trade cards, billheads, pamphlets, chapbooks, broadsides, catalogs, postcards, brochures, advertising novelties, posters, certificates, graphic Americana, labels, dance cards, scrapbooks, die cuts, automobilia, memorabilia, almanacs, jest books, tracts, and other commemorative items. This list includes most anything that is printed and isn't bound in a traditional book format. (The majority of these terms may be found in the enlightening Encyclopedia of Ephemera, which provides a reference point for an understanding of ephemera as "minor transient documents of everyday life," a definition more poetic than it is practical. ${ }^{3}$ )

2. Wallace Stevens, The Collected Poems of Wallace Stevens (New York: Vintage Books, 1982), p. 534 3. Maurice Rickards, Collecting Printed Ephemera (Oxford : Phaidon/Christie's, 1988). as quoted in: Rickards, Maurice and Michael Twyman. The Encyclopedia of Ephemera: A Guide to the Fragmentary Documents of Everyday Life for the Collector, Curator, And Historian (New York : Routledge, 2000), p. v. 
The various types listed above have been broadly categorized in the past as gray literature, street literature, and fugitive publications, but the currently accepted term in LCSH is printed ephemera. The introduction of the word printed - and its implementation as a determinative modifier-is significant. Though such materials may be hard to classify, they do belong to the print tradition.

However, a subject tracing is only valid when a work is about ephemera. More specifically, form and genre tracings allow for a wider range of terms because the MARC 655 field appeals to outside authority for its vocabulary. Oddly enough, the Library of Congress's Thesaurus for Graphic Materials prefers ephemera and adds a see reference from printed ephemera. The Art and Architecture Thesaurus contains an array of terms to describe just about any man-made artifact. In addition to many of the terms listed above, the $A A T$ also offers: bills of lading, death certificates, diplomas, hymns, leases, and proclamations, among a long list of items. The curious aspect of the $A A T$, which is indeed amazingly helpful for description and a fine example of a collaborative project, is the discrepancy in how the term ephemera fits into its hierarchy. As a descriptor, ephemera (which does not subdivide), defined as "Everyday items manufactured for a specific, limited use, and usually intended to be discarded thereafter, especially printed matter on paper," lives under the hierarchy "Object Genres —Object Genres by Cultural or Intellectual Valuation" alongside such peer terms as knickknacks and collectibles. ${ }^{4}$ Specific genres of ephemera, however, such as postcards, broadsides, and posters, fall under "Information Forms-Information Artifacts by Function," where one also finds books. Tellingly, the general term documents also falls under "Object Genres," which may well signify that broad categories of description are best suited as genres and finely focused terms are forms. 
In offering an applicable genre and format lexicon, the $A A T$ also provides perhaps the most succinct library-focused definition of ephemera. Understandably, in many discussions of ephemera, an appeal is made to our primary etymological authority, the Oxford English Dictionary, which reveals two paths of development to the current word. The roots are the Greek stems epi meaning "on" or "in" and hemeros meaning "day." Their combination yields the adjective ephemeron in neuter gender, meaning 'lasting (only) a day." The neuter plural form is ephemera ${ }^{5}$; the source of our modern term that has been extended somewhat to mean "shortlived." This usage can be traced back to Aristotle, who applied the term to insects of very brief life span. From the adjective was derived the noun ephemeris (plural: ephemerides), a term applied very early on to books used to show the placement of celestial bodies on specific days. This word expanded later to include a broader category of other "daily" records. The Oxford Classical Dictionary cites a use of ephemerides meaning diaries. Later uses of ephemerides simply interchange with almanac (which has its own etymology from a root meaning "monthly"). This accounts for examples of books with titles that stretch the meaning to include doggerel (Ephemerides; or, Occasional poems, written in Scotland and South Africa, 1828) and holiday keepsakes (Ephémérides de noël, 1910).

The nineteenth century attests an increase in the use of the related adjectival form, ephemeral, in the application to transitory objects and abstract ideas. One early employment of this adjective to the broad category of printed material was the 1903 publication, Ephemeral Bibelots: A Bibliography of the Modern Chap-books and Their Imitators, by Frederick Winthrop Faxon. The use of the adjective in conjunction with a generic noun seems to have been a standard application for describing printed material from the early nineteenth through the mid-twentieth centuries. The subject heading "ephemeral materials" was used in the

5. I have chosen to observe the grammatical use of ephemera as a plural in this essay, though it presents the same problem as the plural "data," which is very often used as a singular form. Note that some quotations, taken directly from source material, do use ephemera in the singular. 
first edition of Library Literature, indexing an article from 1917, and is still in use there today. Though Library Literature includes a reference to a 1960 article by E. Lenel titled "Cataloging Ephemera," it appears that the noun form was introduced widely into the vocabulary of librarianship following publication of John Lewis's Printed Ephemera: The Changing Uses of Type and Letterforms in English and American Printing in 1962. ${ }^{6}$ This heavily illustrated work, intended as a study of the development of typefaces over six centuries using an assortment of nontraditional printed items, has found a key role in the modern understanding of the shapes of ephemera. Rather quickly, through the 1960s and 1970s, the noun form began to supplant more unwieldy phrases such as ephemeral publications. This process of substantivation created a new meaning for an existing word, combining elements of both ephemera and ephemerides.

However, this new definition didn't make it into general-use dictionaries until a while later. Though a 1983 American Heritage Dictionary presciently includes a definition for ephemera that comprises printed matter, only in the 1990s did a full concept appear in most reference works. Chambers's 21st Century Dictionary (1996) includes the definition "things that are valid or useful only for a short time, especially printed items, such as tickets and posters." The New Oxford American Dictionary (2001) offers the meaning quite congruent with library practice: "items of collectible memorabilia, typically written or printed ones, that were originally expected to have only short term usefulness or popularity." Yet, while the two earlier words seem to have coalesced into one broader meaning, ephemerides does remain in use in some disciplines as a term for celestial tables, and the word in Greek for newspapers is efimerida, a direct descendant. ${ }^{7}$

6. Alan Clinton, Printed Ephemera: Collection Organisation and Access (London: Clive Bingley Ltd, 1981), p. 25.

7. Etymological notes taken from the Oxford English Dictionary (online version: http:// dictionary.oed.com) and the Oxford Classical Dictionary (online version: http://library.nlx.com/) 
Despite the lexical support for the new meaning of ephemera, the word did not arrive in the library profession fully formed. In looking at how librarians, archivists, and collectors determine the boundaries of ephemera, it becomes apparent that most working definitions are based on two major criteria: format, specifically, difference from standard library materials (i.e., fully fledged bibliographical entities) and function (intent or life utility). Format is the most readily identifiable characteristic of ephemera. Broadsides are large and flat and long; pamphlets have a hard time standing up straight on a shelf; anybody can identify postcards and their fanciful cousins, Victorian trade cards. Bound codices, despite the rich history of printing and binding, hew to a remarkably uniform physical type: bulky rectangles, upright candy boxes aligned on a shelf. But those awkward alsorans-die cuts, long unfolded sheets, limp pages unprotected from wear (hastening their demise), even items printed on silk and other textiles are as various as the insects with which they share their name. In fact, it is not uncommon to find the simplest definition formed as a negative: ephemera are nonbook material. Alan Clinton's working definition further points out the issue of difference: "A class of printed or near-print documentation which escapes the normal channels of publication, sale and bibliographical control." ${ }^{8}$ Not only are outward appearances different, but something innate is skewed, uncontrollable, as well.

Chris Makepeace's definition centers on the characteristics "insubstantial" and "not intended to survive the topicality of its message or event." The second qualifier brings out the ideas of function and intent. If a poster was intended to last only as long as the event it advertised, its insubstantial format is understandable. (Programs and souvenirs weren't really intended to be kept that long, were they? Then they don't need to be very sturdy.) Another writer points out that "the major character of ephemeral material is its production by printing in conjunction with a

8. Clinton, p. 15.

9. Chris E. Makepeace, Ephemera : A Book on Its Collection, Conservation, And Use (Aldershot, Hants., England; Brookfield, Vt., U.S.A. : Gower, 1985), p.12-13. 
particular event." 10 This is true with many pieces found in historical archives, which tend to gather materials with connections to events, but much ephemera sit outside chronology, documenting only themselves, such as advertising cards, labels, and other commercial items. The assertion that ephemera are intended to document time-delimited events needs further clarification. The "conjunction" is most specifically in connection with an event as it happening-as precursor (posters, notices) or immediate documentation (programs, souvenirs). This immediacy binds the ephemeral object more tightly to the occasion-and allows that ephemera do act as evidence of an event. There seems to be an inverse relation between the categorization of printed materials and the essence of the information they contain. Although sturdy, fully fledged books can be characterized as texts that have been generated through a process of research, synthesis, and interpretation of facts, ephemera, the most frangible of printed sources, are often the surest eyewitnesses to raw data: the timing of a train; the appearance of an actor on stage; the price of a product. A further factor of function is the idea of currency. Bus tickets have short currency; stock certificates have longer, ${ }^{11}$ challenging a core concept of the generic definition of ephemera-that they are meant to be thrown away. (When? Immediately? After the bonds have matured?) Ephemera have a life cycle to be accounted for, even though the cycle may be quite short.

Definitional tensions lead to practical challenges for librarians. No matter what ephemera are, they are "difficult"12 materials. Format is the most obvious difficulty. As previously stated, many flimsy pamphlets, posters, and cards refuse to adapt to standardized housing. When one looks at the variation of sizes of broadsides, it is natural to wonder if there were ever any truly standard paper sizes available to printers between the fifteenth

10. Hermina G. B Angelescu, "A bit of history in the library attic: challenges of ephemera research," Collection Managementv 25 no. 4 (2001), p. 63.

11. Clinton, p. 18.

12. Clinton, p. 13. 
and nineteenth centuries. As soon as an appropriate box is found to hold a collection of posters, the next accession will be too large to fit. Trade cards and memorabilia often end up scattered in shoe box-size holders. Mylar sleeves and binders offer more control, but then how does one attach an accession number to an item without marring its appearance? A flat book spine ready for a call number label looks positively inviting when compared to the bizarre contours of die cuts and product labels.

But before call numbers can be assigned, description and cataloging must be done. In contrast to books, much of ephemera does not have identifiable authors. Many chapbooks containing simple folk legends and popular ballads don't reveal much about the identity of their creators (nor are they meant to in many cases, considering that many popular texts were pirated). Books, on the other hand, are usually texts for which authorship has a pride of purpose. Because ephemera lack this simply defined "authority," they are often more challenging to catalog and trace. The less that is known about an item, the fewer words there are available to describe it. Because of the lack of standard descriptive information, "ephemera is the stuff of which catalogers' and acquisitions librarians' nightmares are made."13,14

If cataloging is difficult, collection development with ephemera might seem nigh on impossible. One cannot contact producers for standing orders (unless it seems a good idea to cultivate a relationship with a commercial job printer) or get a good lead on where material originates. In most cases, ephemera just show up. Libraries that do collect printed ephemera to document cultural life in their cities often have fantastic collections of posters complete with staple holes attesting that they have been pulled from walls and telephone poles. One book for private

13. Florence M. Jumanville, Introduction to "Printed ephemera, the raw materials of history," LLA Bulletin v 53 (Fall 1990), p. 56.

14. There are catalogers and bibliographers who relish the chance to track down the unrecorded details of difficult-to-catalog pieces, but these pursuits don't make for very efficient workflow. 
collectors of ephemera lists among suggested places to find paper antiques unclaimed storage auctions and transportation auctions (as companies need to get rid of things "passengers left behind"), buildings being torn down, attics and cellars, and libraries(!) (obviously those with little respect for the ephemeral) ${ }^{15}$. Perhaps the most effective way to build a collection is to wait for private collectors to create significant accumulations and then donate or sell them. Though the realization that "there is a chance that even now, broadsheets long vanished may still be discovered under the layers of wallpaper ... in some remote farmhouse" 16 further reinforces the ethereal essence of such things. Left alone long enough, they literally become the fabric of existence. For those among us intrepid enough to attempt to collect proactively, goals have to be set, as with any good collection policy. Do we gather by subject (politics, circus memorabilia), historical eras and events (World Fairs), by functions (theater posters)? Maybe a collection is primarily intended to include examples of printing styles.

One final challenge presents itself as an administrative hot potato: should ephemera be part of printed collections, or should they be under the jurisdiction of archives? The simple answer might seem to be that printed should go with printed. However, owing to the difficulty of cataloging, much ephemera are often gathered into groups; and groups of items brought together because of a common theme-especially nontraditional, flimsy, somewhat rare items-start to sound like prime candidates for archival arrangement. The truth is that many archives are charged with the care and housing of ephemera. A collection of blank postcards that were not used to convey correspondence still look and feel like a group of cancelled mail. Maybe it is the basic need for organization and arrangement that places groups of indisputably

15. Adelaide Hechtlinger and Wilbur Cross. The Complete Book of Paper Antiques (New York, Coward, McCann \& Geoghegan, 1972), p. 11.

16. Robert Collison, The Story of Street Literature: Forerunner of the Popular Press (J. M. Dent and Sons, Ltd. London, 1973), p. 2. 
printed and nonunique items such as programs and Victorian valentines in finding aids rather than bibliographic records. Though at least one writer asserted that archivists often discount ephemera because they are printed, ${ }^{17}$ an agglomeration of pieces can be strongly suggestive to those familiar with archival principles, especially if they document the output of a particular company, artist, or writer. The further wrench in the works is the case of the individual piece. There may be strength in numbers for postcards, but what about the lone poster found among a writer's archives or donated by an alumna? The item can stay in the archives or it can be pulled and added to a poster collection or it can be cataloged separately. ${ }^{18}$ The further complicating aspect when libraries receive items singly is that they are often "devoid of context." ${ }^{19}$ Luckily, we live in a world of format integration, so many answers can be correct. A poster living in an archival arrangement also can have a bibliographic record. Yet, the availability of harmonious cataloging procedures doesn't render the question moot. In the world of backlogs, ephemera are likely to wait a long while before getting fair attention.

Cataloging and housing of ephemera present basic functional questions for librarians, but the broader question of the role ephemeral material plays in research can be equally hard to address. A commitment to provide access to ephemera should follow from recognition of their importance in historical research and their contribution to a strong and diverse collection. Ephemera can provide windows onto aspects of folklore and culture that are not easily found in printed sources. A number of theoretical issues arise from the use of ephemera in research that should be acknowledged by librarians and archivists. What follows are a few key concepts that could be explored in much more depth but are touched upon here. 
The nature of ephemera gives them a curious place in historical research. Because so many of these types of printed items were created specifically for planned events, they differ from other sources of historical documentation. If we can agree that much of history happens unplanned, we rely on eyewitness accounts and reports of the aftereffects for much historical testimony. Ephemera such as playbills, advertising broadsides, and invitations were prepared in advance of events and principally contain information about what was intended to take place.

For many researchers, printed ephemera may be acknowledged, but there is a basic assumption that information about an event-a play, a circus performance, a bus ride-was recorded in a more reliable format, such as the history of a theater company. This assumes that the raw ephemeral format is expendable for purposes of recording information. There should be a greater recognition of the importance of format, of the physical embodiment of information. The form of presentation means something in and of itself, so ephemera may be the most reliable witnesses to an event owing to temporal proximity. In short, ephemera contain primary information. ${ }^{20}$ However, any historical research with ephemera must be counterbalanced with post-event documentation to answer questions such as: Did the actors listed in the playbill appear on stage as indicated? Did a six ton Indian elephant really amaze crowds at the circus? Did Abraham Lincoln show up for the advertised debate? Printed ephemera that present advance knowledge of events must be corroborated with other sources.

Ephemera have risen gradually in the esteem of researchers-just as manuscripts have evolved from the merely artifactual/iconographic to being essential for critical studies, documenting, as they do, the creative process. Photographs, as well, have gone from being merely illustrative to being studied for their self-contained value by social

20. Makepeace, p. 23 
historians and image critics. Ephemera are slowly achieving this type of intellectual and academic gentrification.

In the introduction to the collection of essays, The Other Print Tradition, Cathy Lynn Preston states that the study of "the cheap print tradition" is to confront "elitist constructions of culture." ${ }^{21}$ Forms of printed matter often track directly to the level of society they were aimed at or used by. Poorer classes possessed poorer print, cheap in many senses of the word. Gray literature was just that-blurry, hard to read, obscure. In our present age, we might believe that the book has been universalized, that the majority of people in the world have access to the same format of intellectual transmission - the bound codex-via public libraries and cheap editions. But we cannot confuse the present with the situation of the past, when bound books were a mark of higher culture, higher education, and higher income. What was left-the substandard printed item-was the domain of the poorer classes. "Ephemera" was a good descriptive word for a class of printed material that was as brief as the lives of those who consumed it.

To draw a broad contrast, books are meant to be permanent or, at least, long-lived; posters, broadsides, and postcards are not. The inherent value assumption is that human intellectual culture benefits from ensuring access to certain documents such as Darwin's account of his voyages, whereas the itinerary of a French circus troupe in the early nineteenth century is relegated to the status of a forgettable factoid of quotidian existence. Big ideas trump small details; any type of collection development involves value judgment along these lines. Libraries have long been storehouses of printed records of consequence, playing an active role in the canonization of great ideas, but the details of everyday life, of the fleeting pleasure, deserve their due. For example,

21. Cathy Lynn Preston, "Introduction" p. ix in Cathy Lynn Preston and Michael J. Preston, The Other Print Tradition: Essays on Chapbooks, Broadsides, And Related Ephemera (New York and London : Garland, 1995). 
the contribution that ephemeral publications made to the rise of popular literacy must be acknowledged. ${ }^{22}$

There are other cautions to be noted concerning the use of ephemera in research. Katherine Ott points out that the face value of ephemera must be questioned in the same way as any source. In a cautionary example she gives, one learns that broadside printers often used whatever woodcut they had readily available to illustrate an event, no matter how applicable. Thus, "a news sheet might describe a stabbing but the image might portray a shooting." ${ }^{23}$ Literal interpretation of ephemera must be held in abeyance for very practical reasons. The innocent look of much printed ephemera can mislead one into thinking that they are "more honest and less contrived" than other research sources, but that innocence might hide fundamental errors in the data presented. ${ }^{24}$ The language of much early ephemera, especially, is allegorical and, like kindred primary sources, must be interpreted rather than simply read.

Another interesting point to consider involves the original intent of printed ephemera. They are perhaps the types of primary research materials most closely aligned with commerce. Items such as broadsides, handbills, programs, trade cards, and postcards were often intended, first and foremost, to sell a product or service, not simply record historical data. The nature of commerce-associated ephemera provides a different sort of research value. These items are more widely demonstrative of styles and approaches to popular culture because much of it was created without editorial intervention. As Ott points out, ephemera often display "more drama, magniloquence, and wild claims than other kinds of primary sources." 25

22. Victor E. Neuberg, Popular Literature: A History and Guide From The Beginning of Printing to the Year 1897 (London and Totowa, New Jersey: Woburn Press, 1977), p. 13-15.

23. Ott, p. 16.

24. Ott, p. 12

25. Ott, p. 14 . 
A very heartening thought (or perhaps disheartening for some) is that the age of ephemera has not passed completely. The introduction of duplicating machines and photocopiers over the past century made it easier for many more people to make multiples of printed items, thus continuing the spirit of street literature that had largely died out by the end of the nineteenth century. ${ }^{26}$ But this is a new type of ephemera, which is not intended primarily as a commercial product. Rather, such items as crudely drawn cartoons, joke lists, and even humorous faxes are created mainly to share information. True, this genre may have to be dubbed the Xerox tradition, but it is hard to deny that a subculture of rhymes, images, and humor is still developed from hand to hand and from copier to copier.

Even in light of these wider intellectual issues raised by the uses of ephemera in academic research, libraries are still faced with the question of how to determine what exactly are ephemera. A worthwhile exercise might be to construct a definition that takes in all of the major themes already discussed in hopes of ending up with something similar to the description of archives that anyone who has had the luck to take David Gracy's course in archival endeavor at the University of Texas at Austin has had to memorize. To wit, archives are: "The records, organically related, of an entity, systematically maintained (commonly after they have fulfilled the purpose for which they were created) because they contain information of continuing value." 27 This definition is word heavy because it needs to be. Archives are difficult to explain because rather than being a single thing, the word refers to a class of materials that display an amazing variety among themselves. The word ephemera has the same quality-it is intended to describe substantives but, instead, functions as an abstract.

\footnotetext{
26. Paul Smith, "Models from the Past: Proto-Photocopy-Lore" p. 184 in Cathy Lynn Preston and Michael J. Preston, The Other Print Tradition: Essays on Chapbooks, Broadsides, And Related Ephemera (New York and London : Garland, 1995).

27. This is truly from memory (with a slight bit of prompting)
} 
So if we accept the following statements: Ephemera fall into the general category of what libraries and archives contain by definition. They are items that contain some type of information, some communicative value, often in the form of texts. Ephemera are often intended to document events. Ephemera, in form, generally differ from more substantial printed items, such as books, in that they are very often on or cut from single sheets of papers or simply folded and bound. Ephemera document the impact of commerce on society, and functions of daily life and the substance of popular literacy (including religious thought, news, humor, and entertainment).

Then we might say that: Ephemera are printed artifacts, usually less substantial than books, which, though intended for specific limited purposes or events, are kept by libraries and archives because they contain continuing research value, notably for the study of popular culture.

One goal in defining a word, of course, is to give it validity; and one point of this essay is perhaps not so subtly to add another voice to the argument that ephemera be given their due (as much as possible) in the library and archives world. ${ }^{28}$ Asking that nonbook sources of information be taken more seriously is always a delicate proposition. Especially in this age of ephemeral Web sites, one can imagine even more extremely transient types of information that could be collected: phone calls and interactive chat sessions, maybe even skywriting, messages set in the largest typefaces known, and so on.

But we return to Candy Jernigan and her quest to record the evidence of her life using the widest assortment of artifacts that made themselves known to her. It is telling that Jernigan's term for many of the found innovation in printing, two years before Gutenberg began work on his Bible, that icon of the modern intellectual age, he used movable type to print a piece of ephemera, an indulgence (Lewis, John. Printed ephemera : the changing uses of type and letterforms in English and American printing (Woodbridge, Suffolk, England : Antique Collector's Club, $2^{\text {nd }}$ edition, 1990), p. 11.) 
objects she used in her artwork and journals was "Rejectamenta." ${ }^{29}$ She deliberately sought out materials that were intended to be thrown away as soon as they were exhausted, such as train tickets, paper bags, lottery tickets, and flattened cigarette packages. Among her many projects, though, one seems particularly planned to provoke a reconsideration of the value of evidence left behind. It also is one that ties in very closely to the subject at hand. In 1985, she created the Dead Bug Book, a series of delicate pencil sketches of insect corpses she found in the windowsills and dusty corners of her home in Cape Breton, Nova Scotia. She achieved something singularly beautiful and useful with this project. She documented an aspect of her daily life, and if we remember one of the basic definitions of our topic of discussion, she was, literally, cataloging ephemera. 